\title{
Relationship Between Body Mass Index and Obesity Awareness in School Students
}

\author{
Hassan D. Alasmari ${ }^{\mathrm{a}}$, Abdullah D. Al-Shehria, Tariq A. Aljuaid ${ }^{\mathrm{a}}$, \\ Bassam A. Alzaidia, Khaled A. Alswat ${ }^{\mathrm{b}, \mathrm{c}}$
}

\begin{abstract}
Background: The primary aim was to assess the prevalence of overweight and obesity among the participants and its relationship to obesity awareness.

Methods: A cross-sectional study that included intermediate and high schools students was conducted between April 2014 and June 2015. Anthropometric measurements were obtained by the researchers and body mass index (BMI) was calculated. We used the obesity risk knowledge (ORK-10) scale to assess obesity awareness. Participants who answered $\geq 5$ out of 10 questions correctly were considered to be aware.
\end{abstract}

Result: A total of 528 students were enrolled (mean age, 15.58 years). The mean BMI was $22.37 \mathrm{~kg} / \mathrm{m}^{2}$, and $27.6 \%$ were either overweight or obese. The mean ORK-10 score was 3.15 and $25.4 \%$ were considered to be aware. Compared to those who were non-aware, participants in the aware group were more likely to be older $(\mathrm{P}<0.001)$, male $(\mathrm{P}<0.001)$, attend high school $(\mathrm{P}<0.001)$, eat dinner with their families $(\mathrm{P}=0.021)$, eat fruit at least daily $(\mathrm{P}=0.027)$, and consider obesity to be a disease $(\mathrm{P}<0.001)$.

Conclusion: Only $25.4 \%$ of students who participated were considered to be aware about obesity. Those who were aware were more likely to be older male high school students.

Keywords: Body mass index; Obesity; Awareness; School

\section{Introduction}

Obesity is defined as the presence of a body mass index (BMI) $\geq 30$ and is considered to be one of the fastest growing health problems in the modern world $[1,2]$. A study performed in the US among children and adolescents aged $6-19$ years in $2001-2002$ showed that $31.5 \%$ were at risk for overweight or

Manuscript accepted for publication March 14, 2017

${ }^{a}$ Taif University School of Medicine, Taif, Saudi Arabia

bepartment of Medicine, Taif University School of Medicine, Taif, Saudi Arabia

${ }^{\mathrm{c} C}$ Corresponding Author: Khaled A. Alswat, Department of Medicine, Taif University School of Medicine, Taif, Saudi Arabia. Email: kalswat@hotmail.com

doi: https://doi.org/10.14740/jocmr2987w were overweight, and $16.5 \%$ were obese compared with $29.9 \%$ and $15.0 \%$, respectively in 1999 - 2000 [3]. Another study performed in England showed that the prevalence of overweight and obesity among boys aged $7-11$ years was $17 \%$ and for girls in the same age group, the prevalence was $23.6 \%$ [4]. In the United Arab Emirates, the prevalence in the age group of $5-17$ years was $21.5 \%$ for overweight and $13.7 \%$ for obesity [5]. A study performed in Saudi Arabia in a sample of male school children 6 - 18 years of age showed that $11.7 \%$ of them were overweight and $15.8 \%$ of them were obese [6].

There are several factors that have been found to influence the level of health, such as social environment, education, personal health practices, healthy child development, and culture [7]. Social cognition theory suggests that behavior, which occurs in a social context such as eating and physical activity, is not directly determined by the outside stimulus of a situation, but rather by mediating internal mental processes such as knowledge, attitudes, and beliefs [8].

It is important to establish good health knowledge and attitudes toward overweight and obesity because it is associated with and considered to be an important risk factor for several chronic conditions, including diabetes, heart disease, and joint pain [9]. It is also considered one of the important preventable causes of death worldwide [10].

The awareness levels about the risks associated with obesity are considered to be insufficient. Media are not viewing the obesity-related health problems as suggested by the available evidence [11]. Previous studies have demonstrated that in different developed countries, the majority of persons reveal limited data concerning obesity co-morbidities and the knowledge is even less when asking about obesity as a known risk factor for cancer $[12,13]$.

The primary aim of this study was to assess obesity awareness and knowledge among intermediate and high schools students using a reliable and validated scale, the obesity risk knowledge (ORK-10) scale [14]. Additionally, we assessed the prevalence of overweight and obesity among the participants, and the relationship between the awareness level and BMI, type of school, parent's education, and lifestyle habits.

\section{Methods}

This cross-sectional study included students from intermediate and high schools located in Taif, Saudi Arabia. It was conducted between April 2014 and June 2015 [15]. The research proposal was approved by the ethical committee at Taif Uni- 
Table 1. Baseline Characteristics of the Whole Cohort

\begin{tabular}{|c|c|}
\hline \multicolumn{2}{|l|}{ Baseline characteristics $(\mathrm{N}=\mathbf{5 2 8})$} \\
\hline Mean age (years) & $15.58(\mathrm{SD} 1.801)$ \\
\hline Male $(\%)$ & 82.6 \\
\hline Female $(\%)$ & 17.4 \\
\hline High school students (\%) & 46 \\
\hline Intermediate school students (\%) & 54 \\
\hline Attending governmental school (\%) & 86.9 \\
\hline Mean height $(\mathrm{m})$ & $1.62(\mathrm{SD} 0.11)$ \\
\hline Mean weight (kg) & $59.80(\mathrm{SD} 19.85)$ \\
\hline Mean BMI $\left(\mathrm{kg} / \mathrm{m}^{2}\right)$ & $22.37(\mathrm{SD} 6.006)$ \\
\hline Mean waist circumference $(\mathrm{cm})$ & $79.77(\mathrm{SD} 14.85)$ \\
\hline \multicolumn{2}{|l|}{ Socioeconomic status } \\
\hline Live with both parents (\%) & 89.4 \\
\hline Live in house they own (\%) & 58 \\
\hline Both parents working $(\%)$ & 27.3 \\
\hline Lower level of education (father) (\%) & 47.1 \\
\hline Lower level of education (mother) (\%) & 60.2 \\
\hline \multicolumn{2}{|l|}{ Sleeping habits } \\
\hline Less than $6 \mathrm{~h}$ sleeping/night $(\%)$ & 33.9 \\
\hline More than $8 \mathrm{~h}$ sleeping/night (\%) & 23 \\
\hline \multicolumn{2}{|l|}{ Lifestyle habits } \\
\hline Use electronic device daily (\%) & 79.9 \\
\hline TV in the bed room $(\%)$ & 46 \\
\hline Eating and watch TV $(\%)$ & 68.6 \\
\hline Play video game on a daily basis (\%) & 28.8 \\
\hline \multicolumn{2}{|l|}{ Dietary habit } \\
\hline Daily breakfast eating (\%) & 69.6 \\
\hline Breakfast at home $(\%)$ & 38.3 \\
\hline Lunch with family (\%) & 87.8 \\
\hline Dinner with family $(\%)$ & 85.2 \\
\hline Eating fruit at least once daily (\%) & 20.2 \\
\hline Eating fast food on a daily basis (\%) & 7 \\
\hline Soft drinks at least once daily (\%) & 32.7 \\
\hline \multicolumn{2}{|l|}{ Physical activity } \\
\hline Sedentary life style (\%) & 37.6 \\
\hline $\begin{array}{l}\text { Practicing sports more } \\
\text { than } 300 \mathrm{~min} / \text { week }(\%)\end{array}$ & 17.1 \\
\hline \multicolumn{2}{|l|}{ Transportation } \\
\hline Walking to and from the school daily (\%) & 28.8 \\
\hline \multicolumn{2}{|l|}{ Smoking } \\
\hline Active $(\%)$ & 5.9 \\
\hline Passive $(\%)$ & 46.3 \\
\hline \multicolumn{2}{|l|}{ ORK-10 scale } \\
\hline Mean OKR-10 score (SD) & 3.15 (SD 1.9) \\
\hline Aware $(\%)$ & 25.4 \\
\hline Unaware $(\%)$ & 74.6 \\
\hline \multicolumn{2}{|l|}{ Do you consider obesity as a disease? } \\
\hline Yes $(\%)$ & 83.3 \\
\hline No $(\%)$ & 16.7 \\
\hline
\end{tabular}

versity School of Medicine. Permission was obtained from the local authority in Taif, which represents the local office of the Ministry of Education, to obtain the clinical data and to assess the level of the awareness about the obesity risk.

We included intermediate and high school students, aged
12 - 18 years, who were willing to participate in the study. We excluded students with chronic medical illness, existing psychiatric disorders, and students with learning disabilities.

A total of 11 schools were selected randomly: one school was a private boys' school and the other 10 schools were public schools; of these, seven were boys' schools and three were girls' schools. Four schools out of the 11 were boys' high schools, four were intermediate boys' schools, one was a girls' high school, and two were girls' intermediate schools. One or two classes were selected randomly from each school that was visited by the researchers.

Each student's height and weight were measured by the researchers and BMI was calculated. BMI was categorized as follows: underweight (BMI $<18.5 \mathrm{~kg} / \mathrm{m}^{2}$ ), normal (BMI 18.5 $\leq 24.9 \mathrm{~kg} / \mathrm{m}^{2}$ ), overweight (BMI $25 \leq 30 \mathrm{~kg} / \mathrm{m}^{2}$ ), and obesity $\left(\mathrm{BMI} \geq 30 \mathrm{~kg} / \mathrm{m}^{2}\right)$.

To assess obesity awareness, we used the ORK-10 scale, which contains 10 questions and each question contains three choices: right, wrong, and I do not know. Each question answered correctly on the ORK-10 form is equal to 1 and there were no negative scores. The minimum score was 0 and the maximum score was 10 . Those who answered $\geq 5$ questions correctly were considered to be aware and those who answered $<5$ questions correctly were considered to be unaware.

Personal information was collected through an interview and on a self-reported questionnaire. This questionnaire was tested in one school before the data collection phase to check for errors, ambiguities, and redundancies. The researchers sat with the respondents, explained the rationale of the study and the process, and obtained verbal consent. They handed out the questionnaire, which was then completed immediately. The respondents were given adequate time to complete the questionnaire and the researchers were available to answer any related questions.

Information about related factors such as eating habits, including eating breakfast at home, eating fruit daily, the frequency of eating fast food, and physical activity were self-reported. Time spent sleeping (in hours) per night was obtained and categorized into $<6 \mathrm{~h}, 6-8 \mathrm{~h}$, and $>8 \mathrm{~h}$, and the optimal time was considered to be $6-8 \mathrm{~h}$ of sleep per night. Socialrelated data such as smoking, parent's education, and working and living situation were also recorded.

Data were collected and analyzed using the Statistical Package for the Social Sciences (SPSS) software version 20. The Chi-squared test was used to study the relationship between variables and the independent $t$-test was used to compare between means. We considered a $\mathrm{P}$ value of $\leq 0.05$ to be statistically significant.

\section{Results}

A total of 528 students were enrolled in this study (mean age \pm standard deviation (SD), $15.58 \pm 1.801$ years). Most participants were male and attending a governmental school, $46 \%$ were high school students, and 54\% were intermediate school students (Table 1). The mean height was $1.62 \pm 0.11 \mathrm{~m}$, mean weight was $59.80 \pm 19.85 \mathrm{~kg}$, mean BMI was $22.37 \pm 6.006$ 
Table 2. Groups Based on ORK-10 Score and Awareness Level

\begin{tabular}{|c|c|c|c|}
\hline Baseline characteristic & Aware & Non-aware & P value \\
\hline Students in the group (\%) & 25.4 & 74.6 & $\mathrm{n} / \mathrm{a}$ \\
\hline Mean ORK-10 score & $5.6(\mathrm{SD} 0.8)$ & $2.3(\mathrm{SD} 1.4)$ & $<0.001$ \\
\hline Mean age (years) & 16.1(SD 1.8) & $15.4(\mathrm{SD} 1.8)$ & $<0.001$ \\
\hline Male $(\%)$ & 92.4 & 79.7 & $<0.001$ \\
\hline High school students (\%) & 59.1 & 41.9 & 0.001 \\
\hline Intermediate school students (\%) & 40.9 & 58.1 & \\
\hline Attending governmental school (\%) & 76.5 & 90.4 & $<0.001$ \\
\hline Mean height $(\mathrm{m})$ & $1.66(\mathrm{SD} 0.1)$ & $1.61(0.11)$ & $<0.001$ \\
\hline Mean weight (kg) & $62.3(\mathrm{SD} 20.7)$ & $59.0(\mathrm{SD} 19.5)$ & 0.098 \\
\hline Mean BMI $\left(\mathrm{kg} / \mathrm{m}^{2}\right)$ & $22.4(\mathrm{SD} 6.1)$ & $22.4(\mathrm{SD} 6.0)$ & 0.953 \\
\hline Mean waist circumference $(\mathrm{cm})$ & $80.7(\mathrm{SD} 13.6)$ & $79.5(\mathrm{SD} 15.3)$ & 0.395 \\
\hline \multicolumn{4}{|l|}{ Socioeconomic } \\
\hline Live with both parents (\%) & 92.4 & 88.3 & 0.808 \\
\hline Live in house they own (\%) & 53.8 & 59.3 & 0.264 \\
\hline Both parents working (\%) & 32.6 & 25.3 & 0.091 \\
\hline Lower level of education (father) (\%) & 48.5 & 46.6 & 0.947 \\
\hline Lower level of education (mother) $(\%)$ & 52.7 & 62.7 & 0.265 \\
\hline \multicolumn{4}{|l|}{ Sleeping habits } \\
\hline Less than $6 \mathrm{~h}$ sleeping/night (\%) & 31.3 & 34.7 & 0.700 \\
\hline More than 8 h sleeping/night (\%) & 24.4 & 22.5 & \\
\hline \multicolumn{4}{|l|}{ Lifestyle habits } \\
\hline Use electronic device daily (\%) & 89.4 & 76.6 & 0.030 \\
\hline $\mathrm{TV}$ in the bed room $(\%)$ & 47.3 & 45.5 & 0.930 \\
\hline Eating and watch TV (\%) & 66.7 & 69.0 & 0.555 \\
\hline Play video game on a daily basis (\%) & 28.8 & 28.8 & 0.261 \\
\hline \multicolumn{4}{|l|}{ Dietary habits } \\
\hline Daily breakfast eating (\%) & 66.7 & 70.9 & 0.207 \\
\hline Breakfast at home $(\%)$ & 39.5 & 38.1 & 0.180 \\
\hline Lunch with family (\%) & 85.5 & 88.5 & 0.968 \\
\hline Dinner with family (\%) & 88.6 & 84.3 & 0.021 \\
\hline Eating fruit at least daily $(\%)$ & 22.1 & 19.5 & 0.027 \\
\hline Eating fast food on a daily basis (\%) & 8.4 & 6.4 & 0.658 \\
\hline Soft drinks at least once daily (\%) & 29.5 & 33.9 & 0.687 \\
\hline \multicolumn{4}{|l|}{ Physical activity } \\
\hline Sedentary life style $(\%)$ & 33.1 & 39.0 & 0.794 \\
\hline Practicing sports more than $300 \mathrm{~min} /$ week (\%) & 18.5 & 16.7 & \\
\hline \multicolumn{4}{|l|}{ Transportation } \\
\hline Walking to and from the school daily (\%) & 34.4 & 35.4 & 0.745 \\
\hline \multicolumn{4}{|l|}{ Smoking } \\
\hline Active $(\%)$ & 8.4 & 5.1 & 0.379 \\
\hline Passive $(\%)$ & 45.8 & 46.6 & 0.640 \\
\hline \multicolumn{4}{|l|}{ Do you consider obesity as a disease? } \\
\hline Yes $(\%)$ & 92.4 & 80.7 & $<0.001$ \\
\hline
\end{tabular}




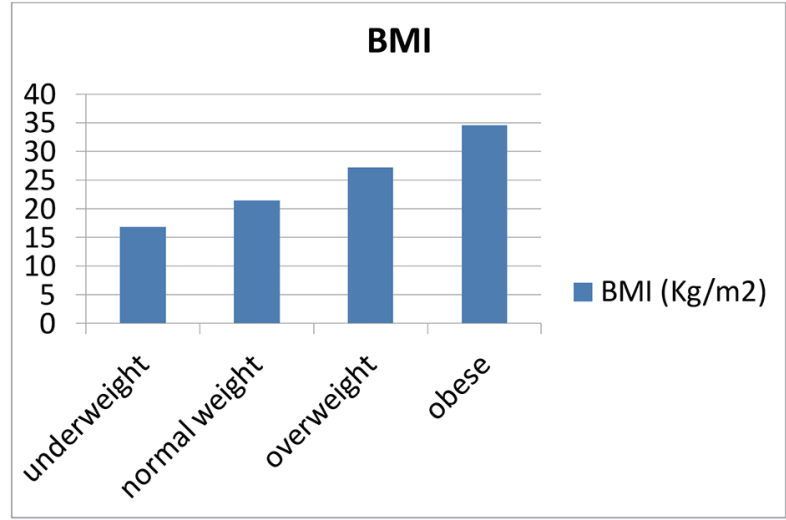

Figure 1. BMI.

$\mathrm{kg} / \mathrm{m}^{2}$, and mean waist circumference was $79.77 \pm 14.85 \mathrm{~cm}$. The BMI distribution for both male and female students was as follows: $33.1 \%$ were underweight, $39.2 \%$ were normal weight, $15.7 \%$ were overweight, and $11.9 \%$ were obese.

Most students' reported living with both parents and $27.3 \%$ of the students reported that both parents were working. Overall, $47.1 \%$ of the students' fathers and $60.2 \%$ of the students' mothers were reported to have a lower level of education (high school or less).

There were $56.9 \%$ of the students who reported optimal sleeping hours per night. Additionally, 79.9\% reported using electronic devices on a daily basis and $25.2 \%$ report using their devices for $\geq 6 \mathrm{~h}$ per day. There were $69.6 \%$ who ate breakfast daily, and $38.3 \%$ reported that they ate breakfast. There were $87.8 \%$ and $85.2 \%$ who ate lunch and dinner, respectively, with family. Additionally, $37.6 \%$ reported a sedentary life style and $17.1 \%$ participated in sports $>300$ min per week. There were $28.8 \%$ of the students who walked to and from school most days.

The mean ORK-10 score was $3.15 \pm 1.9$ and $25.4 \%$ were considered to be aware. We divided the students based on the ORK-10 score into aware and non-aware groups (Table 2). Compared to those who were considered to be non-aware, participants in the aware group were more likely to be older $(\mathrm{P}<$ $0.001)$, male $(\mathrm{P}<0.001)$, attend high school $(\mathrm{P}<0.001)$, use electronic devices daily $(\mathrm{P}=0.030)$, eat dinner with their families $(\mathrm{P}=0.021)$, eat fruit at least daily $(\mathrm{P}=0.027)$, and consider obesity to be a disease $(\mathrm{P}<0.001)$. Both groups tended to have a similar BMI and waist circumference measurements (Figs. 1 and 2). There was no statistical difference between groups for the living situation, the parents' education, sleeping habits, other eating habits, or smoking.

When groups were divided based on BMI category, there

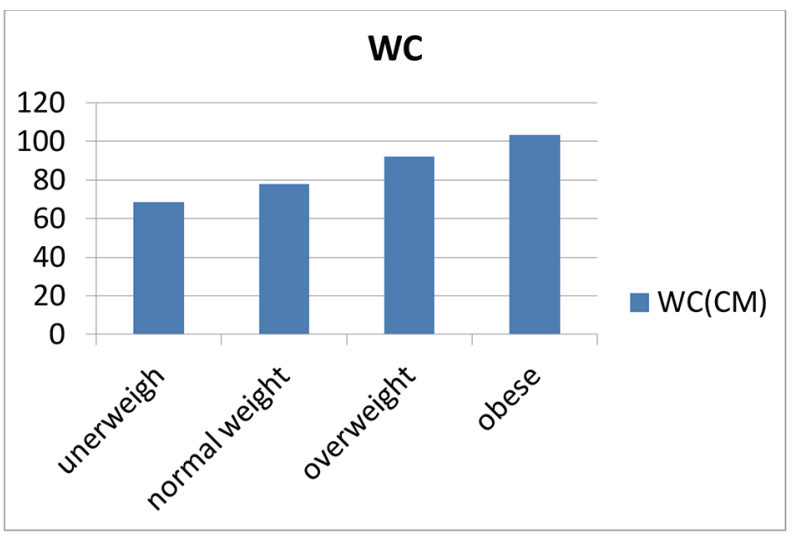

Figure 2. Waist circumference.

was no statistical difference in the obesity awareness level (P $=0.629)$ or in considering obesity to be a disease $(\mathrm{P}=0.650)$ (Table 3).

Adjusting for age, sex, school type, living situation, parents' education, eating habits, walking to and from school, and activity level showed a non-significant negative partial correlation between BMI and ORK-10 score $(\mathrm{r}=-0.027, \mathrm{P}=$ $0.552)$ and between waist circumference and ORK-10 score ( $\mathrm{r}$ $=-0.025, \mathrm{P}=0.580$ ).

\section{Discussion}

Our study showed that only $25.4 \%$ of the participating students were considered to be aware about obesity according to the ORK-10 scale results. Older males who were attending high school were more likely to be aware and were more likely to consider obesity to be a disease.

There were $27.8 \%$ of the students who were either obese or overweight, which is similar to the results of a previous study [6]. The aware group in our study was more likely to eat dinner with their family. The aware students were more likely to eat breakfast daily and at home, but they were also more likely to be active smokers and eat fast food more frequently. A previous study showed that eating meals with a family every day is associated with a lower rate of obesity and maintaining a healthy lifestyle habit [16].

Viewing obesity as disease will help health care providers to diagnose and treat obesity earlier, to prevent potentially related complications. Most of the aware group in our study considered obesity to be a disease compared with the nonaware group. Recently, the medical societies that have also begun considering obesity to be a disease include the American

Table 3. Groups Based on BMI Categories

\begin{tabular}{llllll}
\hline & Underweight & Normal weight & Overweight & Obese & P value \\
\hline Number of students (\%) & 33.1 & 39.3 & 15.7 & 11.9 & n/a \\
Aware (\%) & 25.5 & 26.4 & 22.7 & 25.4 & 0.629 \\
Consider obesity as a disease? & $80 \%$ & $84.1 \%$ & $88 \%$ & $84.1 \%$ & 0.650 \\
\hline
\end{tabular}


Medical Association and the American Association of Clinical Endocrinologists.

Although a previously published study showed that the questionnaire is a valid tool to screen for obesity knowledge in this age group, we are not aware of any other study that was performed to assess the level of awareness in this age group [14]. A recent study used the ORK-10 scale to assess the obesity awareness level among nursing, dietetic, and medical students, and the results showed that the awareness level in each group is positively correlated with the year of the training, and that dietetic students scored the highest using the ORK-10 scale [17].

Our study strengths are using a validated questionnaire (ORK-10) and collecting many related variables including socioeconomic, dietary, sleep, and activity habits. Our study weaknesses include the predominance of males in the study, the small sample size, most of the sample was from governmental schools, and we included only one city.

\section{Conclusion}

Only $25.4 \%$ of the participating students were considered to be aware about obesity. Those who are aware were more likely to be older male high school students.

\section{Acknowledgments}

This manuscript abstract was presented as a poster at the American Association of Clinical Endocrinology 2016 Annual Meeting in Orlando, Florida. The abstract was published in the meeting preceding journal (Endocrine Practice).

\section{Conflicts of Interest}

None.

\section{Funding}

None.

\section{References}

1. Calculator BMI. Basics about Childhood Obesity. Accessed Sept 2016.

2. World Health Organization: Obesity and overweight. Fact sheet No 311. 2012. Accessed Oct 2016.
3. Hedley AA, Ogden CL, Johnson CL, Carroll MD, Curtin LR, Flegal KM. Prevalence of overweight and obesity among US children, adolescents, and adults, 1999-2002. JAMA. 2004;291(23):2847-2850.

4. Lobstein TJ, James WP, Cole TJ. Increasing levels of excess weight among children in England. Int J Obes Relat Metab Disord. 2003;27(9):1136-1138.

5. Malik M, Bakir A. Prevalence of overweight and obesity among children in the United Arab Emirates. Obes Rev. 2007;8(1):15-20.

6. al-Nuaim AR, Bamgboye EA, al-Herbish A. The pattern of growth and obesity in Saudi Arabian male school children. Int J Obes Relat Metab Disord. 1996;20(11):10001005 .

7. World Health Organization. The determinants of health. Geneva. Accessed 12 May 2016.

8. Bless H, Fiedler K, Strack F. Social Cognition: How Individuals Construct Social Reality. Hove, UK: Psychology Press. 2004.

9. World Health Organization. Obesity: Preventing and Managing the Global Epidemic. World Health Organization: Geneva, 2000.Accessed Aug 2016.

10. A community strategy to prevent obesity. Lancet. 2009;374(9688):428.

11. British Nutrition Foundation. Obesity. The Report of the British Nutrition Foundation's Task Force. Blackwell Science: London. 1999.

12. Bocquier A, Verger P, Basdevant A, Andreotti G, Baretge J, Villani P, Paraponaris A. Overweight and obesity: knowledge, attitudes, and practices of general practitioners in france. Obes Res. 2005;13(4):787-795.

13. Obesity as a public health issue: a look at solutions (2003). www.phsi.harvard.edu/health_reform/poll_results.pdf. Accessed Sept 2016.

14. Swift JA, Glazebrook C, Macdonald I. Validation of a brief, reliable scale to measure knowledge about the health risks associated with obesity. Int J Obes (Lond). 2006;30(4):661-668.

15. Alswat KA, Al-shehri AD, Aljuaid TA, Alzaidi BA, Alasmari HD. The association between body mass index and academic performance. Saudi Medical Journal. 2017;38(2):186-191.

16. Yuasa K, Sei M, Takeda E, Ewis AA, Munakata H, Onishi C, Nakahori Y. Effects of lifestyle habits and eating meals together with the family on the prevalence of obesity among school children in Tokushima, Japan: a cross-sectional questionnaire-based survey. J Med Invest. 2008;55(1-2):71-77.

17. Swift JA, Sheard C, Rutherford M. Trainee health care professionals' knowledge of the health risks associated with obesity. J Hum Nutr Diet. 2007;20(6):599-604. 